CLINICAL STUDY

\title{
Association of bone microarchitecture with parathyroid hormone concentration and calcium intake in men: the STRAMBO study
}

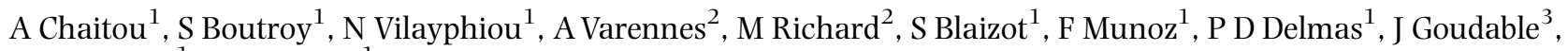 \\ R Chapurlat $^{1}$ and P Szulc ${ }^{1}$ \\ ${ }^{1}$ INSERM Research Unit 1033 and ${ }^{2}$ Central Biochemical Laboratory, Hôpital Edouard Herriot, Université de Lyon 1, Place d'Arsonval, 69437 Lyon, \\ France and ${ }^{3}$ INSERM Research Unit 1060, Lyon, France
}

(Correspondence should be addressed to P Szulc; Email: pawel.szulc@inserm.fr)

\begin{abstract}
Objective: In the elderly, vitamin D deficit, low calcium intake, and impaired bone microarchitecture are associated with higher risk of hip fracture. We assessed the association of bone microarchitecture with calcium intake and serum concentrations of 25-hydroxycholecalciferol (250HD) and parathyroid hormone (PTH) in men.

Design: Cross-sectional analysis was performed in 1064 men aged 20-87 years not taking vitamin D or calcium supplements.

Methods: Daily calcium intake was assessed using a food frequency questionnaire. Bone microarchitecture was assessed at distal radius and tibia by high-resolution peripheral quantitative computed tomography. We measured serum and urinary levels of biochemical bone turnover markers (BTMs). Statistical models were adjusted for age, weight, height, and glomerular filtration rate.

Results: In 500 men aged < 65 years, lower $250 \mathrm{HD}$ levels and low calcium intake were associated with lower trabecular volumetric bone mineral density (Dtrab) at the distal tibia, due to lower trabecular number (Tb.N). Low calcium intake was associated with lower cortical thickness (Ct.Th). Higher PTH level was associated with higher BTM levels. In 563 men aged $\geq 65$ years, the highest PTH quartile was associated with lower Ct.Th (tibia), lower Dtrab (both sites), and lower Tb.N (radius) compared with the lowest quartile. Low calcium intake was associated with lower Tb.N and more heterogenous trabecular distribution. BTM positively correlated with the PTH concentration.

Conclusion: In older men, elevated PTH concentration is associated with high bone turnover, poor trabecular microarchitecture (radius and tibia), and, at the distal tibia, lower Ct.Th. Low calcium intake is associated with lower Tb.N and more heterogenous trabecular distribution.
\end{abstract}

European Journal of Endocrinology 165 151-159

\section{Introduction}

Hip fractures in older men are a public health problem (1). The risk of hip fracture increases in subjects with impaired bone microarchitecture (cortical thinning, deterioration of trabecular connectivity) (2-5). It was also higher in older men with low serum 25-hydroxycholecalciferol (250HD) concentration (6-8). The incidence of hip fracture was higher in the institutionalized elderly men who often suffer from vitamin D deficiency $(8,9)$. Finally, vitamin $\mathrm{D}$ and calcium supplementation reduced the fracture risk in vitamin D-deficient elderly individuals (10-12).

In older home-dwelling men, lower $250 \mathrm{HD}$ level and higher parathyroid hormone (PTH) concentration were associated with lower areal bone mineral density (aBMD) measured by dual energy X-ray absorptiometry (DXA) and higher bone turnover (13). Accelerated bone turnover was associated with impaired bone microarchitecture in men, mainly after 70 years (14). However, association of bone microarchitecture with concentrations of PTH and $250 \mathrm{HD}$ is poorly studied (15).

Our aim was to analyze the relationship of the system PTH-vitamin D-calcium intake with bone microarchitecture at the distal radius and tibia in men aged 20 years and above. Our hypothesis was that bone microarchitecture is associated with the levels of PTH and 250HD and dietary calcium intake in men regardless of age, weight and other confounders.

\section{Materials and methods}

\section{Cohort}

The STRAMBO study is a single-center prospective cohort study of skeletal fragility and its determinants in men (14). It is a collaboration between National 
Institute of Health and Medical Research (INSERM) and Mutuelle de la Région Lyonnaise (MTRL). The study obtained authorization of the local ethics committee and was performed in agreement with the Helsinki Declaration of 1975 and 1983. Letters inviting participation were sent to randomly selected 4500 men aged 20-85 years living in greater Lyon. No specific exclusion criteria were used. The cohort of 1169 men was recruited in 2006-2008. All men provided informed consent, replied to an interviewer-administered epidemiological questionnaire, had bone microarchitecture evaluation, and blood and urine collection.

\section{BMD and bone microarchitecture measurement}

Volumetric BMD (vBMD) and bone microarchitecture were assessed at the nondominant distal radius and the right distal tibia using high-resolution peripheral quantitative computed tomography (HR-pQCT) (XtremeCT; Scanco Medical AG, Brüttisellen, Switzerland). If the participant reported a fracture at this site, the contralateral limb was measured. A stack of 110 parallel CT slices with an isotropic voxel size of $82 \mu \mathrm{m}$ was obtained, thus delivering a 3D representation of a bone segment of $\sim 9 \mathrm{~mm}$ of length in the axial direction. Quality control was monitored by daily scans of a phantom containing rods of hydroxyapatite (HA) embedded in a soft tissue equivalent resin (QRM, Moehrendorf, Germany). Details of mesurements of microarchitecture parameters were previously described (16). Coefficient of variation (CV) for the phantom (100$800 \mathrm{mg} \mathrm{HA} / \mathrm{cm}^{3}$ ) varied from 0.1 to $0.9 \%$. CVs for the microarchitectural parameters assessed in 15 volunteers measured three times varied from 0.7 to $1.5 \%$ for cortical thickness (Ct.Th) and for vBMD: total density (Dtot), cortical density (Dcort), and trabecular density (Dtrab). $\mathrm{CV}$ varied from 2.5 to $4.4 \%$ for trabecular number (Tb.N), thickness (Tb.Th), spacing (Tb.Sp), and spacing standard deviation (Tb.Sp.SD). Scans of poor quality (movement, disrupted contour of cortical bone) were excluded (93 radii, i.e. $8 \%, 46$ tibiae, i.e. 3.9\%).

\section{Bone turnover markers}

Non-fasting serum and urine were collected at $1300 \mathrm{~h}$ and stored at $-80^{\circ} \mathrm{C}(16)$. Serum PTH was measured using a human-specific two-site immunochimiluminescence assay (ELECSYS; Roche). The detection limit was $3 \mathrm{pg} / \mathrm{ml}$. The intra- and inter-assay CVs were $<5 \%$. Serum 250HD was measured with RIA (DiaSorin, Stillwater, MN, USA) after acetonitril extraction. The detection limit was $3 \mathrm{ng} / \mathrm{ml}$. Intraassay CV is $6.9,5.9$, and $4.9 \%$ for the concentrations of 10,19 , and $50 \mathrm{ng} / \mathrm{ml}$ respectively. Interassay CVs were $9-11 \%$. Serum total osteocalcin (OC), N-terminal extension propeptide of type I collagen (PINP) and $\beta$-isomerized C-terminal telopeptide of collagen type I ( $\beta$-CTX) were measured with a human-specific two-site immunochimiluminescence assay (ELECSYS; Roche) (16). For OC, detection limit was $0.5 \mathrm{ng} / \mathrm{ml}$. The interassay $\mathrm{CV}$ varied from 11.1 to $14.6 \%$ for concentrations from 21.4 to $220.5 \mathrm{ng} / \mathrm{ml}$. For PINP, detection limit was $5 \mathrm{ng} / \mathrm{ml}$. Interassay $\mathrm{CV}$ varied from 4.7 to $5.9 \%$ for concentrations from 41 to $766.7 \mathrm{ng} / \mathrm{ml}$. For $\beta$-CTX, detection limit was $0.01 \mathrm{ng} / \mathrm{ml}$. Interassay CV varied from 3.7 to $5 \%$ for concentrations from 0.3 to $2.8 \mathrm{ng} / \mathrm{ml}$. Bonespecific alkaline phosphatase (BAP) was measured with an enzymatic immunoassay (Metra BAP; Quidel, San Diego, CA, USA). Detection limit was $0.7 \mu \mathrm{mol} / \mathrm{l}$. Interassay $\mathrm{CV}$ varied from 2 to $5.9 \%$ for levels from 7.5 to $49.4 \mu \mathrm{mol} / \mathrm{l}$. Urinary total deoxypyridinoline (DPD) was measured after acid hydrolysis by ELISA (Metra Total DPD; Quidel). Detection limit was $0.5 \mathrm{nmol} / \mathrm{l}$. Interassay CV varied from 4.4 to $14.2 \%$ for concentrations between 4.3 and $9.7 \mathrm{nmol} / \mathrm{l}$. Serum calcium, phosphorus, and creatinine were measured by standard laboratory methods (17). Glomerular filtration rate was estimated using the MDRD equation (18).

\section{Covariates}

Average time spent outdoors (h/wk) was estimated on the basis of the overall amount of time spent on walking, gardening, and participating in leisure sport activity including seasonal activities (19). Tobacco smoking was assessed as current smoker versus currently nonsmoker. Calcium intake was estimated using a foodfrequency questionnaire (FFQ) adapted to French alimentary habits (20).

\section{Statistical analysis}

Statistical analyses were made using the SAS 9.1 Software (Cary, NC, USA). Data are presented as mean \pm s.D. or, for non-Gaussian distributed variables, as median and interquartile range. Age-related changes in PTH and 25OHD levels were modeled by the PROC LOESS using the option Automatic Smoothing Parameter Selection. This method provides robust fitting in the presence of outliers. In further analyses, variables with non-Gaussian distribution were log-transformed. Linear regression and simple correlation coefficient were calculated for various cutpoints in order to establish the threshold value of age associated with different age-related trends. Correlation was assessed by Pearson's partial correlation coefficient adjusted for age, weight, height, glomerular filtration rate, and season. Season was classified as four seasons (spring, summer, autumn, and winter) defined by the date of blood collection. The association of bone microarchitectural parameters with PTH and 250HD quartiles was assessed by analysis of covariance. The preliminary models were adjusted for age, weight, height, glomerular filtration rate (all continuous), current 
smoking status (yes versus no), time spent outdoors (log-transformed, quartiles), and season (four classes). As season and time spent outdoors were not significant $(P>0.20)$, they were not retained in the final models. Then, we calculated trend across the quartiles. The difference between the adjusted means in the fourth quartile and in the first quartile was expressed as percentage and number of s.D. and its statistical significance was calculated using the Dunnett-Hsu test. The analyses were also performed in groups classified using the generally accepted thresholds (21, $22)$ : severe vitamin D deficiency $(250 \mathrm{HD}<10 \mathrm{ng} / \mathrm{ml})$, vitamin D deficiency (10-20 ng/ml), vitamin D insufficiency $(20-30 \mathrm{ng} / \mathrm{ml})$, and vitamin D sufficiency ( $>30 \mathrm{ng} / \mathrm{ml}$ ). The association between calcium intake and microarchitectural parameters was assessed, at first, across the quartiles of calcium intake. As these analyses showed similar average values of dependent variables in the three upper quartiles $(P>0.7)$, the analyses were repeated in two groups (lowest quartile versus three upper quartiles of calcium intake). The difference was expressed in percentage and number of S.D.

\section{Results}

\section{Age-related changes in the levels of PTH and $250 H D$}

Men taking vitamin D or calcium supplementation $(n=37), 15$ men who had increased serum levels of both calcium and PTH (possibility of primary hyperparathyroidism), Seven men who did not have biological measurements, one young man with extremely low $250 H D$ concentration as well as men who had scans of poor quality (93 radii, 46 tibiae) were excluded. Men who had scans of poor quality were older $(P<0.01)$, shorter $(P<0.01)$, and more obese $(P<0.001)$. Their PTH and 250HD levels and their calcium intake did not differ from other men.

Serum 250HD level was stable until 65 years $(r=0.05, P=0.38)$ and then was correlated negatively with age $(r=-0.18, \beta=-0.29 \mathrm{ng} / \mathrm{ml}$ per year,
$P<0.001$; Table 1, Fig. 1). Serum PTH level correlated positively with age in men aged $<65$ years $(r=0.19$, $\beta=0.23 \mathrm{pg} / \mathrm{ml}$ per year, $P<0.001)$ and in men aged $\geq 65$ years $(r=0.27, \beta=1.22 \mathrm{pg} / \mathrm{ml}$ per year, $P<0.001)$. On the basis of the inspection of the LOESS curves, linear regression and correlation coefficients (Table 2), this threshold was most discriminative. Thus, the analyses were performed in the two age groups: $<65$ years (480 radii, 500 tibiae) and $\geq 65$ years ( 534 radii, 563 tibiae).

In older men, $250 \mathrm{HD}$ and $\mathrm{PTH}$ concentrations varied according to the season $(P<0.001$ and $P<0.05$ respectively). In winter, $250 \mathrm{HD}$ level was $34 \%$ lower (1.09 S.D., $P<0.001$ ), whereas PTH concentration was $20 \%$ higher $(0.53$ s.D., $P<0.05)$ compared with summer. In younger men, $250 \mathrm{HD}$ varied according to the season $(P<0.001)$, whereas PTH did not $(P=0.18)$. In winter, $250 \mathrm{HD}$ level was $42 \%$ lower (1.21 s.D., $P<0.001)$ compared with summer. The age-adjusted partial correlation coefficient between 250HD and log-transformed PTH varied from $r=0.18 \quad(n=200$, $P<0.01)$ in summer to $r=0.29(n=298, P<0.001)$ during the winter.

\section{PTH and 25OHD versus bone microarchitec- ture and bone turnover marker before the age of 65 years}

In men aged $<65$ years, low calcium intake was associated with lower Ct.Th. Low calcium intake and low 250HD were associated with poor trabecular microarchitecture. Higher PTH level was associated with higher bone turnover rate.

Cortical bone Total bone area (Tt.Ar) and medullary area (Ma.Ar) at the distal radius and tibia did not correlate with the PTH and 250HD levels (Table 2). PTH level weakly correlated negatively with $\mathrm{Ct}$.Th at the distal radius and tibia. In the multivariate models, PTH and 250HD levels were not associated with Dtot, Dcort, and Ct.Th on both the skeletal sites $(P>0.10)$.

Table 1 Descriptive analysis of the 1064 men from the STRAMBO cohort included in the analysis presented in this study.

\begin{tabular}{lcccccccc}
\hline \multicolumn{7}{c}{ Age (years) } \\
\cline { 2 - 9 } & $20-30$ & $31-40$ & $41-50$ & $51-60$ & 61 to $<65$ & $65-70$ & $71-80$ \\
\hline$n$ & 76 & 71 & 89 & 91 & 173 & 144 & 319 & $>80$ \\
Weight (kg) & $75 \pm 10$ & $78 \pm 11$ & $82 \pm 14$ & $80 \pm 11$ & $80 \pm 10$ & $80 \pm 13$ & $77 \pm 12$ & $77 \pm 11$ \\
Height (cm) & $178 \pm 6$ & $175 \pm 7$ & $176 \pm 7$ & $173 \pm 6$ & $171 \pm 6$ & $170 \pm 7$ & $167 \pm 6$ & $166 \pm 5$ \\
Outdoor & $7 \pm 3$ & $7 \pm 4$ & $7 \pm 4$ & $8 \pm 5$ & $9 \pm 5$ & $9 \pm 5$ & $8 \pm 5$ & $6 \pm 4$ \\
Ca intake & $886 \pm 331$ & $788 \pm 291$ & $790 \pm 307$ & $772 \pm 279$ & $777 \pm 240$ & $779 \pm 239$ & $749 \pm 252$ & $749 \pm 256$ \\
Serum Ca & $2.44 \pm 0.13$ & $2.43 \pm 0.11$ & $2.37 \pm 0.13$ & $2.38 \pm 0.15$ & $2.35 \pm 0.17$ & $2.37 \pm 0.16$ & $2.35 \pm 0.19$ & $2.38 \pm 0.15$ \\
Phosphorus & $1.17 \pm 0.13$ & $1.14 \pm 0.15$ & $1.11 \pm 0.15$ & $1.07 \pm 0.16$ & $1.07 \pm 0.15$ & $1.04 \pm 0.16$ & $1.03 \pm 0.15$ & $1.04 \pm 0.17$ \\
GFR & $102.5 \pm 14.8$ & $93.0 \pm 14.3$ & $88.8 \pm 14.8$ & $82.9 \pm 14.2$ & $81.7 \pm 16.8$ & $76.7 \pm 16.3$ & $73.1 \pm 16.5$ & $67.8 \pm 17.3$ \\
PTH & $34.5 \pm 12.1$ & $34.9 \pm 9.9$ & $40.5 \pm 13.0$ & $41.7 \pm 15.2$ & $41.5 \pm 22.1$ & $42.8 \pm 15.2$ & $50.1 \pm 21.8$ & $63.7 \pm 37.6$ \\
25OHD & $21.5 \pm 10.4$ & $24.9 \pm 9.9$ & $25.1 \pm 10.1$ & $23.4 \pm 12.1$ & $24.5 \pm 11.1$ & $22.8 \pm 8.4$ & $21.4 \pm 9.5$ & $17.6 \pm 8.4$ \\
\hline
\end{tabular}

Outdoor, time spent outdoors (hours/week); Ca, calcium intake (mg/day); Serum Ca (mmol/l); phosphorus (mmol/l); GFR, glomerular filtration rate (ml/min); $\mathrm{PTH}$, parathyroid hormone (pg/ml); 25OHD, 25 hydroxycholecalciferol (ng/ml). 

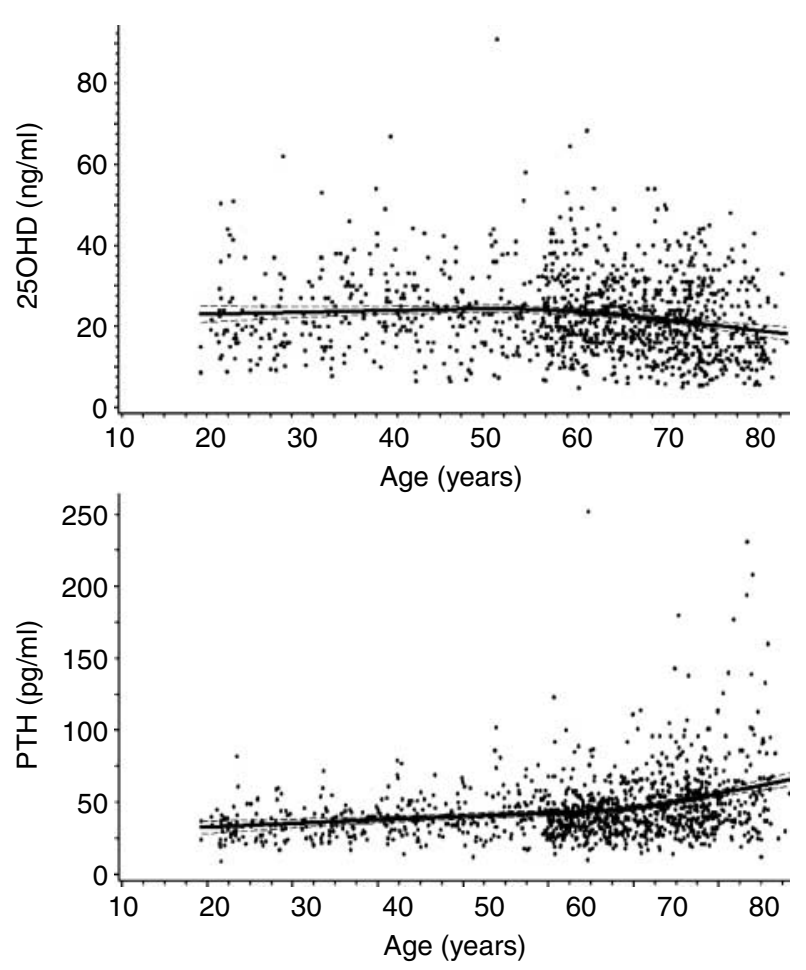

Figure 1 Age-related changes of the concentrations of 25-hydroxycholecalciferol (25OHD) and parathyroid hormone (PTH) in 1063 men aged 20-87 years from the STRAMBO cohort.

Men in the lowest quartile of calcium intake had lower Ct.Th at the distal radius and distal tibia (5.2-6.0\%, 0.29 S.D.) compared with men in the three higher quartiles (Table 3).

Trabecular bone Trabecular parameters of distal tibia correlated weakly but significantly with PTH and 250HD concentrations (Table 2). After adjustment for confounders, trabecular parameters did not vary across PTH quartiles $(P>0.15)$.

At the distal tibia, Dtrab and Tb.N correlated weakly with $250 \mathrm{HD}$ level. In multivariate models, both of them increased across the 250HD quartiles $(P<0.005)$. Men in the lowest 250HD quartile had lower Dtrab $(6.7 \%$, 0.33 S.D., $P<0.05)$ and Tb.N (5.0\%, 0.32 s.D., $P<0.01)$ compared with the highest $25 \mathrm{OHD}$ quartile. Tb.Sp and Tb.Sp.SD decreased across the 250HD quartiles $(P<0.005)$ and were $3.2 \%(0.35$ S.D., $P<0.05)$ lower in the lowest quartile compared with the highest one. Men with $250 \mathrm{HD}<10 \mathrm{ng} / \mathrm{ml}(n=28)$ had lower tibia Dtrab $(10.7 \%, 0.52$ S.D., $P<0.05)$ and lower Tb.N (7.0\%, 0.43 s.D., $P<0.05)$ compared with men who had $250 H D>30 \mathrm{ng} / \mathrm{ml}$. They also had higher Tb.Sp $(4.7 \%$, 0.48 S.D., $P<0.05)$ and higher Tb.Sp.SD $(4.4 \%, 0.44$ S.D., $P<0.05)$. At the radius, trabecular parameters were not associated with $250 \mathrm{HD}$ concentration.

On both the skeletal sites, men in the lowest quartile of calcium intake ( $<600 \mathrm{mg} /$ day) had lower Dtrab and Tb.N, but greater Tb.Sp and Tb.Sp.SD (Table 3).
Bone turnover markers Most of the bone turnover marker (BTM) correlated with the PTH level. After adjustment for confounders, serum OC, BAP, and $\beta$-CTX were $16-44 \%$ higher $(0.35-0.70$ S.D., $P<0.005)$ in the highest PTH quartile than in the lowest PTH quartile. In contrast, BTM levels did not vary across the $250 \mathrm{HD}$ classes or between the calcium intake groups.

\section{Associations between PTH, 25OHD, bone microarchitecture and BTM after the age of 65 years}

Men aged $\geq 65$ years with higher PTH level had lower $\mathrm{Ct} . \mathrm{Th}$ and greater Ma.Ar at the distal tibia, poor trabecular microarchitecture on both skeletal sites, and higher bone turnover rate. Men with low calcium intake had poor trabecular microarchitecture on both skeletal sites.

Table 2 Correlation between PTH and 25OHD and bone microarchitectural parameters at the distal radius and distal tibia (adjusted for age, weight, height, glomerular filtration rate, and season) in two groups of men analyzed in this study.

\begin{tabular}{|c|c|c|c|c|}
\hline & \multicolumn{2}{|c|}{$<65$ years $(n=500)$} & \multicolumn{2}{|c|}{$\geq 65$ years $(n=563)$} \\
\hline & PTH & $25 \mathrm{OHD}$ & PTH & $25 \mathrm{OHD}$ \\
\hline$O C^{a}$ & $0.30^{\dagger}$ & -0.03 & $0.32^{\dagger}$ & -0.04 \\
\hline PINP $^{a}$ & $0.19^{\dagger}$ & -0.03 & $0.16^{\dagger}$ & -0.06 \\
\hline $\mathrm{BAP}^{\mathrm{a}}$ & $0.17^{\dagger}$ & -0.09 & $0.20^{\dagger}$ & -0.03 \\
\hline$\beta$-СТX ${ }^{a}$ & $0.32^{\dagger}$ & -0.07 & $0.27^{\dagger}$ & -0.06 \\
\hline $\mathrm{DPD}^{\mathrm{a}}$ & 0.08 & 0.10 & 0.10 & -0.01 \\
\hline \multicolumn{5}{|l|}{ Radius } \\
\hline Tt.Ar & 0.04 & -0.01 & -0.01 & 0.05 \\
\hline Dtot & -0.10 & 0.08 & -0.07 & 0.03 \\
\hline DCort & -0.11 & 0.06 & 0.05 & -0.01 \\
\hline Ct.Th & $-0.13^{\star}$ & 0.08 & 0.01 & 0.01 \\
\hline Ma.Ar & -0.07 & -0.05 & -0.01 & 0.04 \\
\hline DTrab & -0.05 & 0.06 & 0.09 & 0.06 \\
\hline Tb.N & -0.01 & 0.02 & $-0.15^{\star}$ & 0.06 \\
\hline Tb.Th & -0.07 & 0.04 & -0.11 & 0.04 \\
\hline Tb.Sp ${ }^{a}$ & 0.01 & -0.02 & $0.16^{\dagger}$ & -0.07 \\
\hline Tb.Sp.SD ${ }^{a}$ & 0.01 & -0.03 & $0.16^{\dagger}$ & -0.06 \\
\hline \multicolumn{5}{|l|}{ Tibia } \\
\hline Tt.Ar & 0.08 & 0.01 & 0.07 & 0.00 \\
\hline Dtot & $-0.17^{\dagger}$ & 0.11 & $-0.14^{\dagger}$ & 0.05 \\
\hline DCort & -0.07 & 0.03 & -0.07 & 0.04 \\
\hline Ct.Th & $-0.17^{\dagger}$ & 0.10 & $-0.12^{\dagger}$ & 0.07 \\
\hline Ma.Ar & 0.12 & -0.04 & 0.09 & -0.02 \\
\hline DTrab & -0.10 & 0.11 & $-0.14^{\dagger}$ & 0.03 \\
\hline Tb.N & -0.08 & $0.12^{*}$ & -0.06 & 0.03 \\
\hline Tb.Th & -0.10 & 0.03 & $-0.13^{\dagger}$ & 0.01 \\
\hline Tb.Spa & 0.09 & $-0.12^{\dagger}$ & 0.08 & -0.03 \\
\hline Tb.Sp.SD ${ }^{a}$ & 0.08 & $-0.12^{\dagger}$ & 0.05 & -0.02 \\
\hline
\end{tabular}

${ }^{\star} P<0.005 ;{ }^{\dagger} P<0.001 ; \mathrm{PTH}$, parathyroid hormone $(\mathrm{pg} / \mathrm{ml}) ; 25 \mathrm{OHD}, 25$ hydroxycholecalciferol (ng/ml); OC, osteocalcin $(\mathrm{ng} / \mathrm{ml}) ; \mathrm{BAP}$, bone alkaline phostphatase $(\mu \mathrm{mol} / \mathrm{l})$; P1NP, procollagen type $1 \mathrm{~N}$-terminal propeptide $(\mathrm{ng} / \mathrm{ml}) ; \beta$-CTX, beta isomer of C-terminal telopeptide of type I collagen (ng/ml); DPD, total deoxypiridinoline (nmol/mg creatinine); Tt.Ar, total crosssectional bone area $\left(\mathrm{mm}^{2}\right)$; Dtot, total density $\left(\mathrm{mg} \mathrm{HA} / \mathrm{cm}^{3}\right)$; DCort, cortical density (mg HA/ $\left./ \mathrm{cm}^{3}\right)$; Ct.Th, cortical thickness $(\mathrm{mm})$; Ma.Ar, medullary (marrow) area $\left(\mathrm{mm}^{2}\right)$; Dtrab, trabecular density $\left(\mathrm{mg} \mathrm{HA} / \mathrm{cm}^{3}\right)$; Tb.N, trabecular number $(1 / \mathrm{mm})$; Tb.Th, trabecular thickness $(\mu \mathrm{m}) ;$; Tb.Sp, trabecular separation $(\mu \mathrm{m})$; Tb.Sp.SD, trabecular spacing standard deviation ( $\mu \mathrm{m})$.

${ }^{a}$ Non-Gaussian distribution, median, and interquartile range. 
Table 3 Bone microarchitectural parameters according to the daily calcium intake in men aged $<65$ years and in men aged $\geq 65$ years (mean \pm S.D.).

\begin{tabular}{|c|c|c|c|c|c|c|}
\hline \multirow[b]{2}{*}{ Parameter } & \multicolumn{3}{|c|}{ Men aged $<65$ years } & \multicolumn{3}{|c|}{ Men aged $\geq 65$ years } \\
\hline & $\begin{array}{c}\mathrm{QI}<600 \mathrm{mg} / \mathrm{d} \\
(n=122)\end{array}$ & $\begin{array}{c}\text { QII-IV } \geq 600 \mathrm{mg} / \mathrm{d} \\
(n=378)\end{array}$ & $P^{a}$ & $\begin{array}{c}\text { QI }<590 \mathrm{mg} / \mathrm{d} \\
(n=140)\end{array}$ & $\begin{array}{c}\text { QII-IV } \geq 590 \mathrm{mg} / \mathrm{d} \\
(n=423)\end{array}$ & $P^{a}$ \\
\hline \multicolumn{7}{|l|}{ Radius } \\
\hline Tt.Ar & $378 \pm 66$ & $375 \pm 58$ & 0.69 & $388 \pm 56$ & $398 \pm 64$ & 0.07 \\
\hline Dtot & $315.4 \pm 51.7$ & $331.4 \pm 58.3$ & $<0.01$ & $289.7 \pm 64.5$ & $291.5 \pm 63.6$ & 0.49 \\
\hline DCort & $844 \pm 52$ & $849 \pm 50$ & 0.32 & $786 \pm 72$ & $789 \pm 70$ & 0.88 \\
\hline Ct.Th & $0.78 \pm 0.17$ & $0.83 \pm 0.20$ & $<0.05$ & $0.68 \pm 0.21$ & $0.69 \pm 0.22$ & 0.69 \\
\hline Ma.Ar & $305 \pm 67$ & $297 \pm 62$ & 0.26 & $316 \pm 60$ & $322 \pm 68$ & 0.22 \\
\hline DTrab & $180.8 \pm 34.1$ & $192.5 \pm 34.8$ & $<0.005$ & $165.1 \pm 42.1$ & $173.5 \pm 38.2$ & 0.05 \\
\hline Tb.N & $1.88 \pm 0.21$ & $1.93 \pm 0.23$ & $<0.05$ & $1.80 \pm 0.25$ & $1.87 \pm 0.25$ & $<0.005$ \\
\hline Tb.Th & $80.1 \pm 11.5$ & $83.3 \pm 11.8$ & $<0.01$ & $75.7 \pm 13.4$ & $77.1 \pm 11.6$ & 0.37 \\
\hline Tb.Sp ${ }^{b}$ & $454(414 ; 500)$ & $437(396 ; 484)$ & $<0.05$ & $486(423 ; 551)$ & $456(409 ; 506)$ & $<0.01$ \\
\hline Tb.Sp.SD ${ }^{b}$ & $188(166 ; 218)$ & $180(160 ; 201)$ & $<0.005$ & $209(178 ; 261)$ & $196(169 ; 226)$ & $<0.01$ \\
\hline \multicolumn{7}{|l|}{ Tibia } \\
\hline Tt.Ar & $828 \pm 126$ & $835 \pm 122$ & 0.50 & $842 \pm 122$ & $845 \pm 129$ & 0.59 \\
\hline Dtot & $309.8 \pm 52.0$ & $323.2 \pm 54.4$ & $<0.05$ & $279.5 \pm 59.9$ & $286.8 \pm 56.6$ & 0.17 \\
\hline DCort & $877 \pm 39$ & $880 \pm 41$ & 0.55 & $828 \pm 61$ & $831 \pm 59$ & 0.61 \\
\hline Ct.Th & $1.28 \pm 0.25$ & $1.35 \pm 0.26$ & $<0.05$ & $1.17 \pm 0.30$ & $1.18 \pm 0.29$ & 0.73 \\
\hline Ma.Ar & $681 \pm 128$ & $679 \pm 127$ & 0.88 & $706 \pm 132$ & $702 \pm 134$ & 0.73 \\
\hline DTrab & $181.2 \pm 38.2$ & $191.2 \pm 38.3$ & $<0.01$ & $166.9 \pm 38.9$ & $172.8 \pm 37.4$ & 0.08 \\
\hline Tb.N & $1.78 \pm 0.28$ & $1.86 \pm 0.29$ & $<0.005$ & $1.67 \pm 0.28$ & $1.76 \pm 0.30$ & $<0.005$ \\
\hline Tb.Th & $84.9 \pm 12.4$ & $85.8 \pm 12.1$ & 0.48 & $83.3 \pm 13.9$ & $82.7 \pm 13.1$ & 0.53 \\
\hline Tb.Sp & $477(432 ; 548)$ & $455(403 ; 518)$ & $<0.005$ & $504(448 ; 600)$ & $495(425 ; 555)$ & $<0.005$ \\
\hline Tb.Sp.SD ${ }^{b}$ & $224(189 ; 259)$ & $205(176 ; 243)$ & $<0.001$ & $237(205 ; 293)$ & $228(189 ; 270)$ & $<0.005$ \\
\hline
\end{tabular}

OC, osteocalcin ( $\mathrm{ng} / \mathrm{ml}$ ); BAP, bone-specific alkaline phostphatase ( $\mu \mathrm{mol} / \mathrm{l}) ; \mathrm{P} 1 \mathrm{NP}, \mathrm{N}$-terminal propeptide of type I procollagen (ng/ml); $\beta$-CTX, beta-

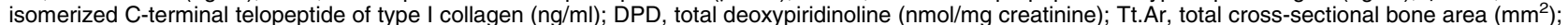
Dtot, total density $\left(\mathrm{mg} \mathrm{HA} \mathrm{cm}^{3}\right)$; DCort, cortical density $\left(\mathrm{mg} \mathrm{HA} / \mathrm{cm}^{3}\right)$; Ct. Th, cortical thickness (mm); Ma.Ar, medullary (marrow) area (mm²); Dtrab, trabecular density $\left(\mathrm{mg} \mathrm{HA} / \mathrm{cm}^{3}\right)$; Tb.N, trabecular number (1/mm); Tb.Th, trabecular thickness $(\mu \mathrm{m})$; Tb.Sp, trabecular separation $(\mu \mathrm{m})$; Tb.Sp.SD, trabecular spacing standard deviation $(\mu \mathrm{m})$.

${ }^{a}$ All the models are adjusted for age, weight, height, smoking, glomerular filtration rate, and 25OHD concentration.

${ }^{b}$ Variables showing non-Gaussian distribution, presented as median and interquartile range, the analyses performed in the log-transformed variables.

Cortical bone Ct.Th at the distal tibia correlated negatively with PTH (Table 2). Otherwise, Tt.Ar, Ma.Ar, and cortical parameters at the distal radius and tibia did not correlate with the PTH and 25OHD levels.

In multivariate models, $\mathrm{Ct}$.Th at the distal tibia decreased across the increasing PTH quartiles $(P<0.05$; Fig. 2). It was $8.3 \%$ lower (0.39 s.D., $P<0.005)$ in the highest PTH quartile than in the lowest quartile. Also at the distal tibia, Ma.Ar increased across the PTH quartiles $(P<0.05)$. After adjustment for confounders, Ma.Ar was $4.3 \%$ higher (0.26 S.D., $P<0.05)$ in the highest PTH quartile compared with the lowest quartile. At the distal radius, cortical parameters did not vary across the PTH quartiles.

At both the skeletal sites, Dcort and Ct.Th did not correlate with the $250 \mathrm{HD}$ level. They did not vary across the 250HD quartiles either $(P>0.25)$. In multivariate models, cortical parameters did not differ between 45 men with severe vitamin D deficiency $(<10 \mathrm{ng} / \mathrm{ml})$ and 99 men with normal 250HD $(25 \mathrm{OHD} \geq 30 \mathrm{ng} / \mathrm{ml})$.

In similar models, Dcort and Ct.Th did not differ between men with the lower calcium intake $(<590 \mathrm{mg} /$ day, lowest quartile) and higher calcium intake except slightly lower Ct.Th at the tibia (Table 3).
Trabecular bone Dtrab correlated negatively with the PTH level and decreased across the PTH quartiles (Table 2, Fig. 2). At both the skeletal sites, men in the highest PTH quartile had $6.7-9.1 \%$ lower trabecular vBMD (0.31 and 0.44 S.D., $P<0.001)$ and $3.6-3.8 \%$ lower Tb.Th $(0.24$ s.D. and 0.25 s.D., $P<0.05)$ in comparison with the lowest PTH quartile. At the distal radius, men in the highest PTH quartile had also lower Tb.N and higher Tb.Sp.SD.

Trabecular parameters did not correlate with the $250 H D$ level. They did not vary according to the $250 \mathrm{HD}$ quartiles nor according to the pre-defined groups.

At both the skeletal sites, men with low calcium intake $(<590 \mathrm{mg} /$ day $)$ had lower Tb.N and slightly lower Dtrab, but higher Tb.Sp and Tb.Sp.SD compared with men who had higher calcium intake.

Bone turnover markers PTH was significantly correlated with the BTM levels (Table 2). In the highest PTH quartile, the BTM levels (except DPD) were 24-52\% higher $(0.42-1.45$ S.D., $P<0.001)$ compared with the lowest PTH quartile (Fig. 3). In the lowest 250HD quartile, BTM levels was slightly higher compared with the higher quartiles, but differences were not statistically significant. The BTM levels did not vary between the calcium intake groups. 

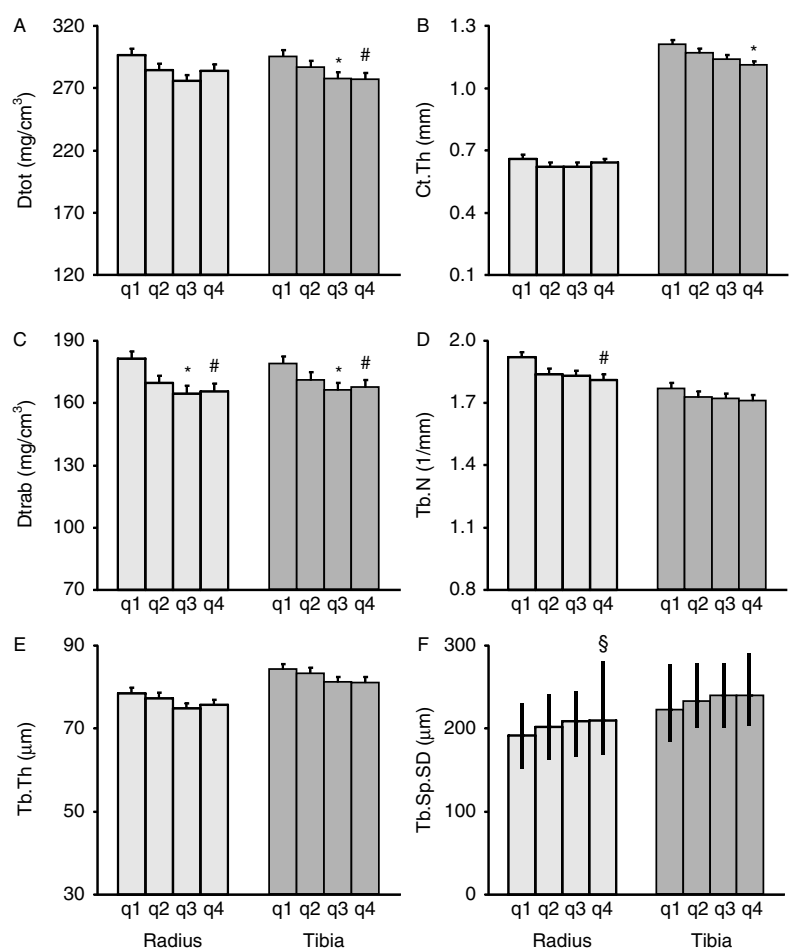

Figure 2 Microarchitectural parameters at the distal radius (pointed bars) and distal tibia (hatched bars) according to quartiles of the PTH concentration in men aged $\geq 65$ years: $\mathrm{q} 1,<35 \mathrm{pg} / \mathrm{ml}$, q2, $35-45.9 \mathrm{pg} / \mathrm{ml}, \mathrm{q} 3,46-59 \mathrm{pg} / \mathrm{ml}, \mathrm{q} 4,>59 \mathrm{pg} / \mathrm{ml}$. All the models are adjusted for age, weight, height, smoking, and glomerular filtration rate: (A) Dtot, total density $\left(\mathrm{mg} \mathrm{HA} / \mathrm{cm}^{3}\right)$ : radius, $F=2.82, P<0.05$, $P$ for trend $=0.06$, tibia, $F=3.53, P<0.05, P$ for trend $<0.005$; (B) Ct.Th, cortical thickness $(\mathrm{mm})$ : radius, $F=1.28, P=0.28, P$ for trend $=0.41$, tibia, $F=2.79, P<0.05, P$ for trend $<0.005$; (C) Dtrab trabecular density $\left(\mathrm{mg} \mathrm{HA} / \mathrm{cm}^{3}\right)$ : radius, $F=4.32, P=0.005$, $P$ for trend $<0.005$, tibia, $F=3.35, P<0.05, P$ for trend $<0.01$; (D) Tb.N, trabecular number $(1 / \mathrm{mm})$ : radius, $F=3.73, P<0.05$, $P$ for trend $=0.005$, tibia, $F=1.47, P=0.22, P$ for trend $=0.13$; (E) Tb.Th, trabecular thickness $(\mu \mathrm{m})$ : radius, $F=2.74, P<0.05$, $P$ for trend, $P<0.05$, tibia, $F=2.12, P=0.10, P$ for trend $<0.05$; (F) Tb.Sp.SD, trabecular number distribution $(\mu \mathrm{m})$ : radius, $F=4.59$, $P<0.005, P$ for trend $<0.005$, tibia, $F=1.94, P=0.12$; $P$ for trend $=0.06$. Data are presented as adjusted mean and S.E.M. for $(A)$ to $(E)$ and as unadjusted median and interquartile range for $(F)$. Symbols for the adjusted difference compared with the first quartile: ${ }^{\star} P<0.01,{ }^{\#} P<0.005,{ }^{\S} P<0.001$.

\section{Discussion}

We found that early afternoon non-fasting PTH level correlated positively with age in men. Serum 250HD level correlated negatively with age in men aged 65 years and above. Before the age of 65 years, men with low $250 H D$ level had lower Tb.N and higher Tb.Sp.SD at the distal tibia, whereas men with low calcium intake had lower Tb.N and higher Tb.Sp.SD at both the skeletal sites. After the age of 65 years, men with the increased PTH level had slightly lower $\mathrm{Ct}$.Th at the distal tibia and lower Dtrab (due to lower Tb.N) at both the skeletal sites. Low calcium intake was associated with lower Tb.N and higher Tb.Sp.SD. BTM levels correlated positively with the PTH level but not with $250 H D$ or calcium intake.

Age-related changes in the early afternoon PTH levels are similar to the PTH measurements in blood collected after overnight fasting, which is consistent with the importance of the endogenous regulation of the circadian PTH secretion $(23,24)$.

Before 65 years of age, 250HD was positively associated with trabecular microarchitecture at the distal tibia. PTH and 250HD were poorly associated with other bone microarchitectural parameters and these associations became non-significant in fully adjusted models. Vitamin D and calcium intake contribute to bone mineral accrual during growth $(25,26)$. By contrast, in adult men, current vitamin D status is weakly correlated with $\operatorname{BMD}(15,27,28)$. In young and middle-aged men, 250HD was weakly correlated positively with BMD at the lumbar spine and the hip (13). The relationship between the PTH level and the BMD in young and middle-aged adults was weak or non-significant $(15,29,30)$. Thus, current PTH secretion does not seem to be a significant determinant of bone mass and microarchitecture in young adult men, although these men may be in the phase of slow bone loss (31).

After the age of 65 years, high PTH level was associated with slightly lower bone mass mainly in the trabecular compartment of distal radius. The inverse associations of PTH level with Ct.Th at the distal tibia and with Tb.N at the distal radius suggest that higher bone resorption triggers this process. Positive
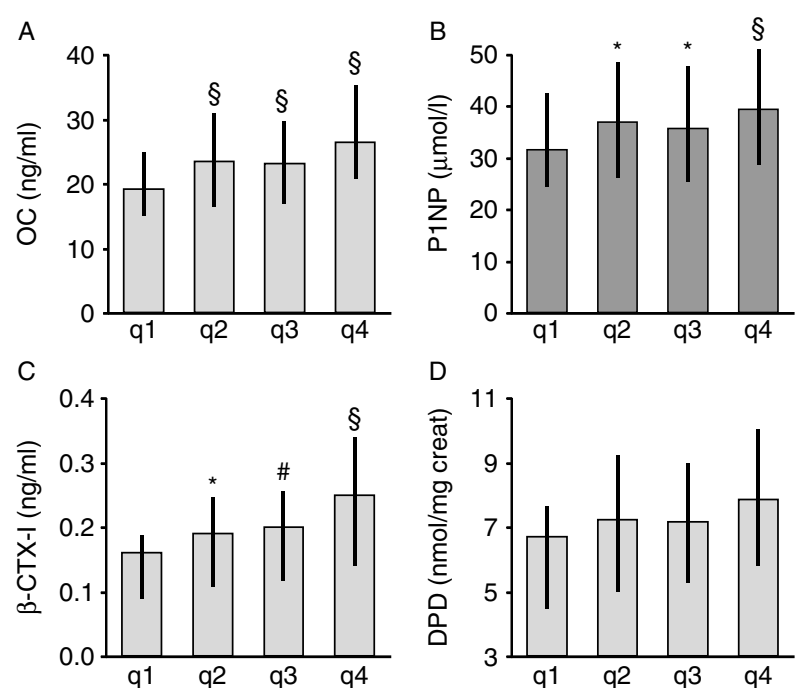

Figure 3 Biochemical bone turnover markers according to the quartiles of PTH concentration in men aged $\geq 65$ years: q1, $<35 \mathrm{pg} / \mathrm{ml}$, q2, 35-45.9 pg/ml, q3, 46-59 pg/ml, q4, >59 pg/ml. All the models are adjusted for age, weight, height, smoking, and glomerular filtration rate: (A) osteocalcin, $F=21.1, P<0.001, P$ for trend $<0.001$; (B) P1NP, $F=5.33, P<0.005, P$ for trend $<0.001$; (C) $\beta$-CTX, $F=13.6, P<0.001, P$ for trend $<0.001$; (D) total deoxypyridinoline, $F=1.18, P=0.32, P$ for trend $=0.12$. ${ }^{*} P<0.01$, ${ }^{\#} P<0.005,{ }^{\S} P<0.001$. 
association between the levels of PTH and BTM in this study and poor bone microarchitecture in men with high bone turnover found previously show that secondary hyperparathyroidism may stimulate bone turnover and contribute to the deterioration of bone microarchitecture (14). At the distal tibia, Ct.Th decreased and Ma.Ar increased, whereas Tt.Ar did not vary across the PTH quartiles. It suggests that cortical thinning due to secondary hyperparathyroidism depends on endocortical resorption and trabecularization of the inner cortical bone (32). However, trabecularized cortical bone (now in the trabecular compartment) may have higher vBMD than the genuine trabecular bone. If so, trabecularization of the cortical bone would falsely increase Dtrab in the highest PTH quartile and artifactually attenuate the inverse association of the PTH concentration with Tb.N or Tb.Th.

The relationship between bone microarchitecture and $250 H D$ level was weak as in the previous data (15). Data on the relationship between DXA-measured aBMD and 250HD concentration in older people are discrepant $(13,33)$. Recently, the association of the 250HD level with hip aBMD and with whole body bone mineral content in a large cohort of men and women was weakly positive, whereas it was not significant with quantitative ultrasound parameters (34).

In our study, lower calcium intake was associated with impaired trabecular microarchitecture irrespective of age. Data on the relationship between calcium intake and bone mass in adult men are discrepant $(35,36)$. Appropriate calcium intake seems to maintain bone mass in the elderly $(37,38)$. This relationship may depend not only on calcium itself but also on the better general nutritional status in people with higher calcium intake (39). The cross-sectional study does not allow to assess temporal relationship. The association of calcium intake with bone microarchitecture but not with the current bone turnover rate suggests that higher current calcium intake may reflect dietary patterns from the youth. In our study, calcium intake is probably underestimated and not accurate. However, our data raise a possibility that low calcium intake contributes to the deterioration of bone microarchitecture in older men.

Strengths of our study are the large cohort and assessment of bone microarchitecture at the weightbearing tibia and non-weight-bearing radius. Our study has limitations. Home-dwelling volunteers may be sicker among young men and healthier among older men. Given the response rate of $26 \%$, it can result in under-representation of older men with severe vitamin $\mathrm{D}$ deficit. The cross-sectional design limits inference on the cause and effect. Calcium intake assessment may be suboptimal due to simplified FFQ and approximate coefficients used to estimate calcium content of products. We collected biological samples in the standardised way in the early afternoon and after an non-standardised lunch that could contain dairy products. This limitation may influence mainly concentrations of PTH and $\beta$-CTX (40). Although our data are in line with analyses based on the fasting blood samples, minor differences cannot be excluded. Low average $250 \mathrm{HD}$ levels suggests that a substantial percentage of men are vitamin $\mathrm{D}$ deficient. However, considerable differences between laboratories exist and our laboratory was not cross-calibrated with other centers measuring 250HD in the time of measurements (41). In the HR-pQCT, Tb.Th, Tb.Sp, and Ct.Th are calculated, not measured. In men with low TbTh, it may result in underestimation of Tb.N. Erroneous estimation of Ct.Th and Dcort may exist, mainly in old men with thin cortex. HR-pQCT underestimates Ct.Th compared with micro-CT; however, the correlation between the methods was very high (42). It indicates that the trends found in our study correspond most probably to the real biological trends; however, absolute values of the means are not accurate.

In conclusion, the association of bone microarchitecture with serum PTH and 250HD levels and with calcium intake in men aged $<65$ years was relatively poor. Thus, in this age range, current calcium and vitamin D status may be weak determinants of bone microarcitecture. After 65 years of age, higher PTH level and lower calcium intake correlated weakly but significantly with poor bone microarchitecture, mainly in the trabecular compartment. Correlation of PTH level with BTM levels and with bone microarchitecture suggests the importance of current PTH secretion for bone status in this age group. In contrast, the association of calcium intake with trabecular microarchitecture, but not BTM levels, rather suggests the importance of long-term dietary habits. The poor association may partly depend on the cohort consisting of home-dwelling men who rarely have extreme vitamin D deficit. It also raises a possibility that a substantial part of the hip fracture risk related to vitamin D deficit depends on the lower muscle mass and higher risk of fall (43). However, despite the limitations of the cross-sectional study, our data support the view that, in the elderly, higher calcium intake and lower PTH concentrations can be beneficial for bone microarchitecture and bone strength.

\section{Declaration of interest}

The authors declare that there is no conflict of interest that could be perceived as prejudicing the impartiality of the research reported.

\section{Funding}

This study was supported by grants from the Roche pharmaceutical company, Basle, Switzerland, from Agence Nationale de la Recherche (ANR-07-PHYSIO-O23-01), from Abondement ANVAR (E1482.042), and from Hospices Civils de Lyon (UF21667).

\section{Acknowledgements}

The authors thank all the technicians from the INSERM 1033 Unit and from the Central Laboratory of the Hôpital Edouard Herriot for their excellent technical assistance. 


\section{References}

1 Johnell O \& Kanis JA. An estimate of the worldwide prevalence and disability associated with osteoporotic fractures. Osteoporosis International 200617 1726-1733. (doi:10.1007/s00198-0060172-4)

2 Black DM, Bouxsein ML, Marshall LM, Cummings SR, Lang TF, Cauley JA, Ensrud KE, Nielson CM \& Orwoll ES. Proximal femoral structure and the prediction of hip fracture in men: a large prospective study using QCT. Journal of Bone and Mineral Research 200823 1326-1333. (doi:10.1359/jbmr.080316)

3 Power J, Loveridge N, Lyon A, Rushton N, Parker M \& Reeve J. Bone remodeling at the endocortical surface of the human femoral neck: a mechanism for regional cortical thinning in cases of hip fracture. Journal of Bone and Mineral Research 200318 1775-1780. (doi:10. 1359/jbmr.2003.18.10.1775)

4 Mayhew PM, Thomas CD, Clement JG, Loveridge N, Beck TJ, Bonfield W, Burgoyne CJ \& Reeve J. Relation between age, femoral neck cortical stability, and hip fracture risk. Lancet 2005 366 129-135. (doi:10.1016/S0140-6736(05)66870-5)

5 Blain H, Chavassieux P, Portero-Muzy N, Bonnel F, Canovas F, Chammas M, Maury P \& Delmas PD. Cortical and trabecular bone distribution in the femoral neck in osteoporosis and osteoarthritis. Bone 200843 862-868. (doi:10.1016/j.bone.2008.07.236)

6 Cauley JA, Parimi N, Ensrud KE, Bauer DC, Cawthon PM, Cummings SR, Hoffman AR, Shikany JM, Barrett-Connor E \& Orwoll E. Serum 25 hydroxyvitamin D and the risk of hip and nonspine fractures in older men. Journal of Bone and Mineral Research 201025 545-553. (doi:10.1359/jbmr.090826)

7 Looker AC \& Mussolino ME. Serum 25-hydroxyvitamin D and hip fracture risk in older US white adults. Journal of Bone and Mineral Research 200823 143-150. (doi:10.1359/jbmr.071003)

8 Lips P. Vitamin D deficiency and secondary hyperparathyroidism in the elderly: consequences for bone loss and fractures and therapeutic implications. Endocrine Reviews 200122 477-501. (doi:10.1210/er.22.4.477)

9 Bischoff-Ferrari HA, Can U, Staehelin HB, Platz A, Henschkowski J, Michel BA, Dawson Hughes B \& Theiler R. Severe vitamin D deficiency in Swiss hip fracture patients. Bone 200842 597-602. (doi:10.1016/j.bone.2007.10.026)

10 Bischoff-Ferrari HA, Willett WC, Wong JB, Giovannucci E, Dietrich T \& Dawson-Hughes B. Fracture prevention with vitamin D supplementation. A meta-analysis of randomized controlled trials. Journal of the American Medical Association 2005293 2257-2264. (doi:10.1001/jama.293.18.2257)

11 Chapuy MC, Arlot ME, Duboeuf F, Brun J, Crouzet B, Arnaud S, Delmas PD \& Meunier PJ. Vitamin D3 and calcium to prevent hip fractures in the elderly women. New England Journal of Medicine 1992327 1637-1642. (doi:10.1056/NEJM199212033272305)

12 Boonen S, Lips P, Bouillon R, Bischoff-Ferrari HA, Vanderschueren D \& Haentjens P. Need for additional calcium to reduce the risk of hip fracture with vitamin $\mathrm{D}$ supplementation: evidence from a comparative metaanalysis of randomized controlled trials. Journal of Clinical Endocrinology and Metabolism 200792 1415-1423. (doi:10.1210/jc.2006-1404)

13 Szulc P, Munoz F, Marchand F, Chapuy MC \& Delmas PD. Role of vitamin $\mathrm{D}$ and parathyroid hormone in the regulation of bone turnover and bone mass in men: the MINOS study. Calcified Tissue International $2003 \mathbf{7 3}$ 520-530. (doi:10.1007/s00223-0022103-5)

14 Chaitou A, Boutroy S, Vilayphiou N, Munoz F, Delmas PD, Chapurlat R \& Szulc P. Association between bone turnover rate and bone microarchitecture in men - the STRAMBO study. Journal of Bone and Mineral Research 201025 2313-2323. (doi:10.1002/jbmr.124)

15 Khosla S, Melton LJ III, Achenbach SJ, Oberg AL \& Riggs BL. Hormonal and biochemical determinants of trabecular microstructure at the ultradistal radius in women and men. Journal of Clinical Endocrinology and Metabolism 200691 885-891. (doi:10. $1210 /$ jc.2005-2065)
16 Boutroy S, Bouxsein ML, Munoz F \& Delmas PD. In vivo assessment of trabecular bone microarchitecture by high-resolution peripheral quantitative computed tomography. Journal of Clinical Endocrinology and Metabolism 200590 6508-6515. (doi:10. 1210/jc.2005-1258)

17 Bacchetta J, Boutroy S, Vilayphiou N, Juillard L, GuebreEgziabher F, Rognant N, Sornay-Rendu E, Szulc P, Laville M, Delmas PD, Fouque D \& Chapurlat R. Early impairment of trabecular microarchitecture assessed with HR-pQCT in patients with stage II-IV chronic kidney disease. Journal of Bone and Mineral Research 201025 849-857. (doi:10.1359/jbmr. 090831)

18 Levey AS, Bosch JP, Lewis JB, Greene T, Rogers N \& Roth D. A more accurate method to estimate glomerular filtration rate from serum creatinine: a new prediction equation. Modification of Diet in Renal Disease Study Group. Annals of Internal Medicine 1999130 461-470.

19 Szulc P, Duboeuf F, Marchand F \& Delmas PD. Hormonal and lifestyle determinants of appendicular skeletal muscle mass in men: the MINOS study. American Journal of Clinical Nutrition 2004 80 496-503.

20 Fardellone P, Sebert JL, Bouraya M, Bonidan O, Leclercq G, Doutrellot C, Bellony R \& Dubreuil A. Evaluation de la teneur en calcium du régime alimentaire par autoquestionnaire fréquentiel. Revue du Rhumatisme et des Maladies Ostéo-Articulaires 199158 99-103.

21 Holick MF. Vitamin D deficiency. New England Journal of Medicine 2007357 266-281. (doi:10.1056/NEJMra070553)

22 Malabanan A, Veronikis IE \& Holick MF. Redefining vitamin D insufficiency. Lancet 1998351 805-806. (doi:10.1016/S01406736(05)78933-9)

23 Fatayerji D \& Eastell R. Age-related changes in bone turnover in men. Journal of Bone and Mineral Research 199914 1203-1210. (doi:10.1359/jbmr.1999.14.7.1203)

24 el-Hajj Fuleihan G, Klerman EB, Brown EN, Choe Y, Brown EM \& Czeisler CA. The parathyroid hormone circadian rhythm is truly endogenous - a general clinical research center study. Journal of Clinical Endocrinology and Metabolism 199782 281-286. (doi:10. $1210 /$ jc. 82.1 .281 )

25 Rizzoli R, Bianchi ML, Garabédian M, McKay HA \& Moreno LA. Maximizing bone mineral mass gain during growth for the prevention of fractures in the adolescents and the elderly. Bone 201046 294-305. (doi:10.1016/j.bone.2009.10.005)

26 Bonjour JP, Carrie AL, Ferrari S, Clavien H, Slosman D, Theintz G \& Rizzoli R. Calcium-enriched foods and bone mass growth in prepubertal girls: a randomized, double-blind, placebo-controlled trial. Journal of Clinical Investigation 199799 1287-1294. (doi:10. 1172/JCI119287)

27 Högström M, Nordström A \& Nordström P. Relationship between vitamin $\mathrm{D}$ metabolites and bone mineral density in young males: a cross-sectional and longitudinal study. Calcified Tissue International 200679 95-101. (doi:10.1007/s00223-006-0049-8)

28 Välimäki VV, Alfthan H, Lehmuskallio E, Löyttyniemi E, Sahi T, Stenman UH, Suominen H \& Välimäki MJ. Vitamin D status as a determinant of peak bone mass in young Finnish men. Journal of Clinical Endocrinology and Metabolism 200489 76-80. (doi:10. 1210/jc.2003-030817)

29 Taha W, Chin D, Silverberg AI, Lashiker L, Khateeb N \& Anhalt H. Reduced spinal bone mineral density in adolescents of an UltraOrthodox Jewish community in Brooklyn. Pediatrics 2001107 E79. (doi:10.1542/peds.107.5.e79)

30 Rucker D, Ezzat S, Diamandi A, Khosravi J \& Hanley DA. IGF-I and testosterone levels as predictors of bone mineral density in healthy, community-dwelling men. Clinical Endocrinology 2004 60 491-499. (doi:10.1111/j.1365-2265.2004.02006.x)

31 Riggs BL, Melton LJ, Robb RA, Camp JJ, Atkinson EJ, McDaniel L, Amin S, Rouleau PA \& Khosla S. A population-based assessment of rates of bone loss at multiple skeletal sites: evidence for substantial trabecular bone loss in young adult women and men. Journal of Bone and Mineral Research 200823 205-214. (doi:10.1359/jbmr. 071020) 
32 Zebaze RM, Ghasem-Zadeh A, Bohte A, Iuliano-Burns S, Mirams M, Price RI, Mackie EJ \& Seeman E. Intracortical remodelling and porosity in the distal radius and post-mortem femurs of women: a cross-sectional study. Lancet 2010375 1729-1736. (doi:10. 1016/S0140-6736(10)60320-0)

33 Bischoff-Ferrari HA, Kiel DP, Dawson-Hughes B, Orav JE, Li R, Spiegelman D, Dietrich T \& Willett WC. Dietary calcium and serum 25-hydroxyvitamin D status in relation to BMD among U.S. adults. Journal of Bone and Mineral Research $200924935-942$. (doi:10.1359/jbmr.081242)

34 Kuchuk NO, Pluijm SM, van Schoor NM, Looman CW, Smit JH \& Lips P. Relationships of serum 25-hydroxyvitamin D to bone mineral density and serum parathyroid hormone and markers of bone turnover in older persons. Journal of Clinical Endocrinology and Metabolism 200994 1244-1250. (doi:10.1210/jc.20081832)

35 Owusu W, Willett WC, Feskanich D, Ascherio A, Spiegelman D \& Colditz GA. Calcium intake and the incidence of forearm and hip fractures among men. Journal of Nutrition $1997 \mathbf{1 2 7}$ 1782-1787.

36 Metz JA, Morris CD, Roberts LA, McClung MR \& McCarron DA. Blood pressure and calcium intake are related to bone density in adult males. British Journal of Nutrition $1999 \mathbf{8 1}$ 383-388. (doi:10.1017/S0007114599000665)

37 Gennari C. Calcium and vitamin D nutrition and bone disease of the elderly. Public Health Nutrition 20014 547-559. (doi:10. 1079/PHN2001140)
38 Nguyen TV, Center JR \& Eisman JA. Osteoporosis in elderly men and women: effects of dietary calcium, physical activity, and body mass index. Journal of Bone and Mineral Research 200015 322-331. (doi:10.1359/jbmr.2000.15.2.322)

39 Dawson-Hughes B. Interaction of dietary calcium and protein in bone health in humans. Journal of Nutrition $2003133852 \mathrm{~S}-854 \mathrm{~S}$.

40 Talbot JR, Guardo P, Seccia S, Gear L, Lubary DR, Saad G, Roberts ML, Fradinger E, Marino A \& Zanchetta JR. Calcium bioavailability and parathyroid hormone acute changes after oral intake of dairy and nondairy products in healthy volunteers. Osteoporosis International 199910 137-142. (doi:10.1007/s001980050208)

41 Lips P, Chapuy MC, Dawson-Hughes B, Pols HA \& Holick MF. An international comparison of serum 25-hydroxyvitamin D measurements. Osteoporosis International 19999 394-397. (doi:10.1007/ s001980050162)

42 MacNeil JA \& Boyd SK. Accuracy of high-resolution peripheral quantitative computed tomography for measurement of bone quality. Medical Engineering \& Physics 200729 1096-1105. (doi:10.1016/j.medengphy.2006.11.002)

43 Bischoff-Ferrari HA, Dawson-Hughes B, Willett WC, Staehelin HB, Bazemore MG, Zee RY \& Wong JB. Effect of vitamin D on falls: a meta-analysis. Journal of the American Medical Association 2009 291 1999-2006. (doi:10.1001/jama.291.16.1999)

Received 18 March 2011

Accepted 11 April 2011 